\title{
Colloidion Baby: A Treatment Challenge for Dermatologist and Neonatologist
}

Adeesh Jain ${ }^{1}$, Deepak Sharma ${ }^{1}$ and Aakash Pandita ${ }^{2}$

${ }^{1}$ Department of Pediatrics, PGIMS, Rohtak, Haryana, India

${ }^{2}$ Department of Pediatrics, GMC, Jammu, India

"Corresponding author: Deepak Sharma, Maheshwari Hospital, Bhatinda, Punjab, India, Tel: +919462270002; E-mail: dr.deepak.rohtak@gmail.com

Rec date: 15 Oct 2014; Acc date: 17 Oct 2014; Pub date: 20 Oct 2014

Copyright: (c) 2014 Jain A et al. This is an open-access article distributed under the terms of the Creative Commons Attribution License, which permits unrestricted use, distribution, and reproduction in any medium, provided the original author and source are credited.

Case

A term male newborn with birth weight of $3.4 \mathrm{~kg}$ with normal Apgar score of 8/9/9 was referred within hours of birth because of presence of parchment like skin all over the body. The detailed examination showed broad thick scales all over the body with predominance over chest, abdomen and upper limbs. There was associated eversion of eyelids and lips. There were excess of scales around face giving appearance of fish like mouth (Figures 1 and 2). There was no other associated anamoly. The infant was managed with adequate humidification with fluid and electrolytes management. Topical application of emollients was done as applied as advised by dermatologist. The scales resolved over next three weeks and baby was discharged. The genetic analysis showed mutation in TGM1 Gene located on chromosome 14q12 which confirmed the diagnosis of Lamellar ichthyosis.

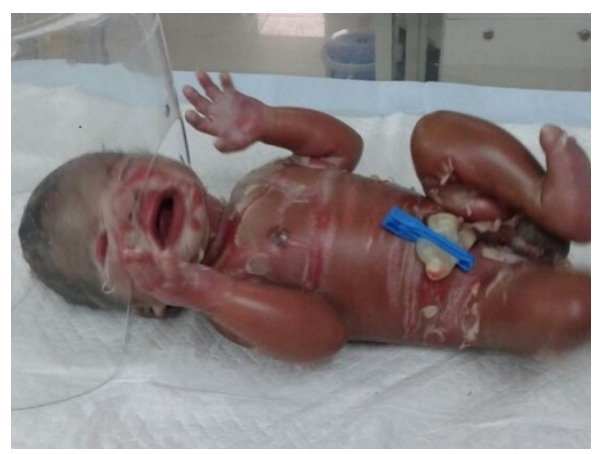

Figure 1: Broad thick scales all over the body with predominance over chest, abdomen and upper limbs (Note: There is excess of scales around face giving appearance of fish like mouth)

\section{Discussion}

Lamellar ichthyosis (ichthyosis lammellaris/nonbullous congenital ichthyosis), is a rare autosomal recessive inherited skin disorder, with incidence of 1 in 600,000. The affected newborns are born in a collodion membrane which is a shiny waxy outer layer to the skin [1]. This membrane is shed 10-14 days after birth with exposure of underlying skin having extensive scaling because of hyperkeratosis. These newborns are usually premature and small for gestational age. As the skin is parchment like at birth, hence they have distortion of facial features with ectropion, eclabium and false contracture of fingers. The biopsy of the skin is nonspecific with and shows compact and thickened stratum corneum [2]. There are many conditions associated with collodion baby and include [3]
- Lamellar Icthyosis

- Non bullous ichthyosiserythroderma

- X-linked ichthyosis

- Netherton syndrome

- Gaucher disease

- Trichothiodystrophy (Tay syndrome)

- Sjogren-Larsen syndrome

- Lamellar exfoliation of the newborn

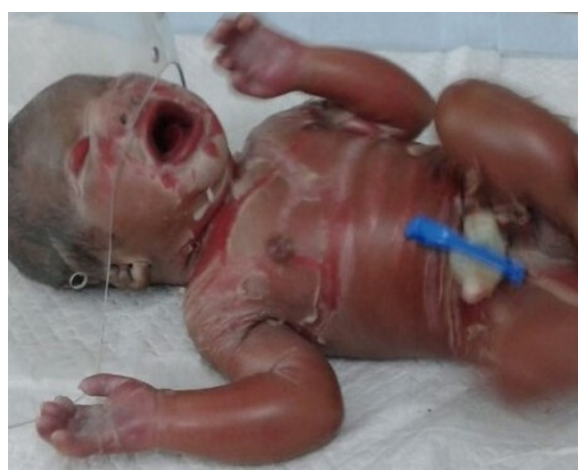

Figure 2: Broad thick scales all over the body with predominance over chest, abdomen and upper limbs (Note: There is excess of scales around face giving appearance of fish like mouth)

Careful history taking include family history, evolution of skin condition and associated malformations should be sought. The Lamellar Ichthyosis (LI) is most commonly associated with collodion baby. The most common type LI1 involves mutation of TGM1 gene on chr14q12 [4]. Treatment involves proper humidification, fluid and electrolyte balance, strict asepsis, bland occlusive ointment emollient application, prevention of overheating, eye care and genetic counselling of the parents for further pregnancy depending upon the diagnosis. Gene therapy is also paving this way in the treatment and may become an important tool in future [5]. The eyes must be protected by using artificial tears, band occlusive dressing or surgical intervention. Manual removal of the skin is not recommended. Usually the thickened stratum corneum get resolves within 2 to 4 weeks [6].

\section{Author's Contribution}

Dr Deepak Sharma and Dr Aakash made the primary manuscript, took the photographs and helped in writing manuscript, Dr Adeesh Jain did final corrections of manuscript before submission. 
Citation: Jain A, Sharma D, Pandita A (2014) Colloidion Baby: A Treatment Challenge for Dermatologist and Neonatologist. J Neonatal Biol 3: I-101. doi:10.4172/2167-0897.1000I-101

Page 2 of 2

\section{References}

1. Van Gysel D, Lijnen RL, Moekti SS, de Laat PC, Oranje AP (2002) Collodion baby: a follow-up study of 17 cases. J Eur Acad Dermatol Venereol 16: 472-475.

2. Vahlquist A, Bygum A, Gånemo A, Virtanen M, Hellström-Pigg M, et al (2010) Genotypic and clinical spectrum of self-improving collodionichthyosis: ALOX12B, ALOXE3, and TGM1 mutations in Scandinavian patients. J Invest Dermatol 130: 438-443.

3. Schmuth M, Martinz V, Janecke AR, Fauth C, Schossig A, et al. (2013) Inherited ichthyoses/generalized Mendelian disorders of cornification. Eur J Hum Genet 21: 123-133.
4. Ivich JM (2014) Ichthyosis in the Neonatal Setting. Adv Neonatal Care 18.

5. Sigurdsson H, Baldursson BT (2014) Inverting Sutures With Systemic Retinoids and Lubrication Can Correct Ectropion in Ichthyosis. Ophthal Plast Reconstr Surg .

6. Abdul-Wahab A, Qasim W, McGrath JA1 (2014) Gene therapies for inherited skin disorders. Semin Cutan Med Surg 33: 83-90. 